\title{
Performance Comparison of Controllers for Solar PV Water Pumping Applications
}

\author{
Kamlesh Yadav $^{1}$, O.S.Sastry ${ }^{1 *}$, R. Wandhare ${ }^{2}$, N. Sheth ${ }^{2}$, M. Kumar ${ }^{1}$, B. Bora ${ }^{1}, \operatorname{Rashmi} \operatorname{Singh}^{1}{ }^{1}$ Renu $^{1}$ and A. Kumar ${ }^{1}$. \\ ${ }^{1}$ National Institute of Solar Energy, India \\ ${ }^{2}$ Indian Institute of Technology Bombay, India and Kisan Solar, Ahmedabad, India \\ *sastry284@gmail.com, Telefax No. : +91-124-2579207
}

\begin{abstract}
This paper presents a detailed comparison of two different electronic controllers used for driving Solar Photovoltaic water pumping systems in India. A recently developed Sine-wave Pump Controller with MPPT (SPCM) having two stage converter topology offered better performance throughout the operational range, over the most popular controllers using the Variable Frequency Drives (VFD). This paper presents an exhaustive study of SPCM and VFD based controllers in terms of their operational performance at $10 \mathrm{~m}$, $18 \mathrm{~m}$ and $20 \mathrm{~m}$ head, in terms of quality of output power and quantity of the total water delivered when connected to the same motorpump set under similar conditions. SPCM with best MPPT efficiency of 99.4\%, lowest THD of less than $3 \%$ and pumped 30 to $70 \%$ more water for same heads. The overall system efficiency of SPCM based pump is $18 \%$ higher than VFD based pumping system for the head corresponding to duty point. The output power quality of SPCM is considerably high, with superior sine-wave (crest-factor 1.42 and 1.56 for voltage \& current), ensures no voltage spikes even at 60 meters of cable length. Thus, the paper establishes performance dominance of SPCM over the VFD based controller through the measurement on actual sample.
\end{abstract}

Keywords-VFD; Pump Controller; Solar PV pump; MPPT;Sinusodial pump controller with MPPT

\section{INTRODUCTION}

Water and energy are the most primary requirements for the world. Use of solar energy for fulfilling the energy requirements is one of the best solutions, due to abundance and easy available nature of the source. However water and solar energy are interlinked with each other for human growth, which include pumping of water for irrigation and drinking water, detoxification of water using Bio based photo sensitizing substances [Avetta et al. 2013], pumped hydro energy storage [Rehmana et al. 2015], production, storing and utilization of hydrogen through electrolysis of water using SPV power [Shin et al. 2015] etc. In case of dye-sensitized solar cell, water can be used to prepare cellulosic electrolytes [Chiappone et al. 2014]. This paper deals with the utilization of solar energy for water pumping requirement. In India, the energy requirement for irrigation is very high, approximately 90 million hectare irrigated land area is there in the country as per the report of ministry of statics and Program Implementation, Government of India [www.mospi.nic.in]. The report describes that $62 \%$ of irrigated land is based on tube wells, $26 \%$ on canals, $3 \%$ on tanks and $9 \%$ by other resources. Main medium for pumping of water is through diesel pump sets or grid based pumps. The recent growth in solar photovoltaic market, incentives by the Government of India [www.mnre.gov.in] and reduction in the cost of solar based pumps are the main reasons for increase in the demand for Solar Photovoltaic (SPV) based water pumps in the country. Recently Ministry of New and Renewable Energy Resources (MNRE), under Jawaharlal Nehru National Solar Mission (JNNSM) has announced a target of about 0.5 million SPV water pumping systems to be deployed in the country by 2020 [www.mnre.gov.in]. Successful implementation of such an ambitious program depends on the performance and reliability of SPV pumping systems. Concurrently, with Government of India's initiatives strenuous efforts are also made by industries for development of efficient pumping system. India has good manufacturing base of conventional water pumping system both, for surface and submersible pumps which are used with conventional grid power. The industry has now started developing motors and pumps suitable for SPV applications such as BLDC motors, variable frequency motor and pumps to be used in JNNSM. However, only those models of SPV water pumping systems will be allowed to be provided with incentive which is qualified by the approved certification centers identified by MNRE under JNNSM. The National Institute of Solar Energy (NISE) is one of the three approved certification centers of MNRE for SPV pumps. NISE has established the test rig and other facilities for evaluation of SPV water pumping systems under real field conditions.

The performance of SPV water pumping systems is not accurate in real field, as estimated because of poor design of the array size, improper pumps and its balance of system (BOS). Extensive research works were reported on the performance estimation, optimum sizing of photovoltaic pumps and the effect of dynamic head variation on pump efficiency [Cuadrosa, 2004; Glasnovica 2007; Dursuna, 2014; Mozaffari Niapour, 2011; Ebaida, 2013; Hamidata, 2009; Senol, 2012; Sastry, 2013; Benghanem, 2014; Moulay-Idriss, 2013 and Kassem 2012]. However, one of the major bottlenecks in the design of high quality SPV water pumping system is to develop a suitable controller with MPPT and variable frequency inverter to drive the motors with optimum efficiency. In India under JNNSM, the AC induction motor based SPV pumps installed in the field are used with VFD without MPPT or Constant voltage based MPPT, along with PWM output. It has been observed that performance of both 
controllers without MPPT and with constant voltage MPPT drops with an increase in dynamic head or module temperature respectively. Having Buck type converter design and too high DC operating voltage is one of the reasons for large difference in water output in summer and winter season even though the radiation on module plane is same. Lots of people have done research on the MPPT algorithms, based on constant voltage, perturb and observe, and incremental conductance methods [Moulay-Idriss, 2013; Kassem, 2012; and Mohammedi, 2014] and effect of power quality on motor insulation [Persson, 1992; Bonnett, 1996; Melhorn, 1995; Hyypio, 1997; Daugherty, 1990 and Mecker, 1992]. Industry grade VFDs are traditionally used for solar water pumping systems to drive induction motors, however limitations in the performance of VFD encouraged researcher to design a new pump controller such as Sine-wave Pump Controller with MPPT (SPCM). In SPCM, the improvement is incorporated by using perturb and observe MPPT algorithm for optimum PV power tracking, variable frequency concept and as well as sinusoidal power output without harmonics \& voltage spikes for longer life by preventing insulation damage of motor.

The main objective of this work is to present a detailed performance comparison between SPV pumps using controllers based on VFD having no MPPT and, newly developed SPCM. The study is done based on parameters such as quantity of the water discharged at a given head, energy efficiency, MPPT efficiency, tracking performance, threshold wattage value to water discharge, power quality, THD, voltage spikes, etc. This study will help to improve the quality and life of solar PV pumping system in real field.

\section{SYSTEM DESCRIPTION}

Fig. 1(a) shows a typical block diagram of industry grade VFD based pump. A three phase inverter is associated with its controller which manages the variable voltage and frequency based on the operating conditions (radiation level and panel temperature).

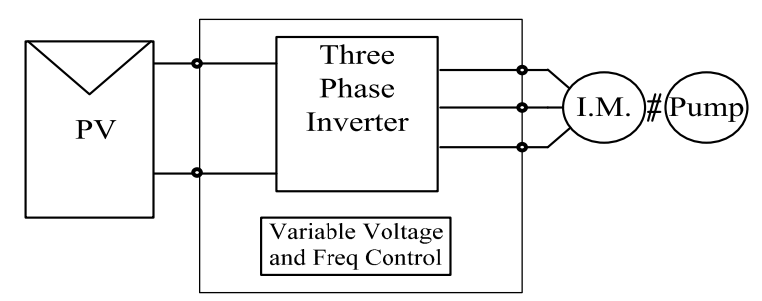

(a)

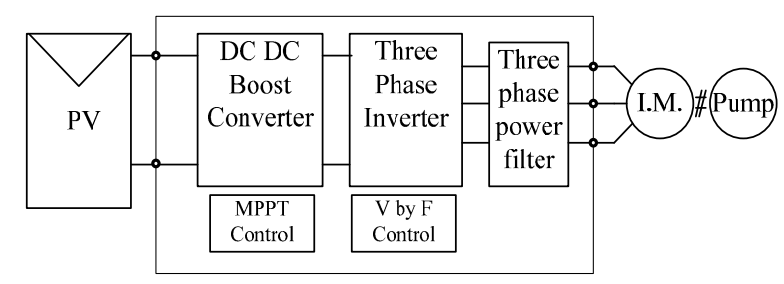

(b)

Fig. 1. Block diagram of (a) VFD and (b) SPCM

Fig.1 (b) shows a modified power converter stages for SPCM dedicated SPV water pumping system. Input PV stage is a conventional DC-DC boost converter and MPPT algorithm used for maximum power extraction from PV array during operating conditions. The input stage is followed by three phase inverter which is controlled by using V/F technique so that to maintain a constant flux throughout the operation. This stage is further followed by three phase power filter whose cut off frequency is adjusted such that it eliminates the higher order harmonics and pass only fundamental component. This reduces the losses in machine and ensures no voltage spikes at the motor terminals.

\section{EXPERIMENTAL SETUP}

The PV pumping test facility established at NISE mainly consists of a sump well (4 m x $2.5 \mathrm{~m} \times 2.5 \mathrm{~m}$ ) and overhead platform of $(3.5 \mathrm{~m} \times 2 \mathrm{~m} \times 2 \mathrm{~m})$ which can create suction head up to $7 \mathrm{~m}$ and a total static head up to $75 \mathrm{~m}$ including the friction head [Sastry et al, 2013]. Flow meters are installed in the facility for a continuous monitoring of the flow of water and pressure gauges are used to maintain the total dynamic head (TDH) of operation. In this study same $3 \mathrm{hp}$ efficient surface pump is used as load with both controllers, keeping the suction head constant at $7 \mathrm{~m}$ and total dynamic head up to $20 \mathrm{~m}$. For investigating the performance of two controllers based on different technologies, a Solar array simulator make: Terra SAS (ETS600X), 15 KVA capacities is used and, for power measurements, a power analyzer make: Zimmer (LMG-450) is used with the pump controllers. The PV array simulator provides a means of comparing the performance by simulating exactly the same PV characteristics during experimentation on VFD and SPCM. The TerraSAS software also records the data of PV power, voltage, current and timestamping. A DSP oscilloscope (DPO 4034) Tektronics make is used for analyzing the wave forms. To benchmark the results during the experiment, the day's radiation profile is maintained using the array simulator. The whole day sun profile is accelerated 10 times faster than a normal day for ease of experimentation. Accordingly, the complete operation of a day is condensed 
proportionately to 55 minutes. The data sampling interval for electrical measurements is 5 milliseconds, and for water output the sampling interval is 1 minute. All the experimental results are recorded using PV simulator software, power analyzer and DSO.

\section{RESULTS AND DiSCUSSIONS}

A comparison of performance features of SPCM and VFD pump controllers of $3 \mathrm{hp} \mathrm{capacities} \mathrm{are} \mathrm{presented.} \mathrm{The} \mathrm{comparison} \mathrm{is}$ made mainly in terms of three parameters (A) Energy efficiency and MPP tracking efficiency of controllers (B) Quality of the power fed to motor \& pump, and (C) Total quantity of the water pumped under the same irradiance profile and PV power. These details are discussed in the following three sections. For the sake of confidentiality the details of manufacturer's brand and name are not revealed.

\subsection{Power tracking efficiency}

To extract maximum power from the PV array a controller's power electronics circuit should have an arrangement for tracking and operating near the maximum power point on the I-V curve of PV array, at any intensity during the time of a day. As per the details supplied by the manufacturer, SPCM has an in-built Maximum Power Point Tracker (MPPT), but most of the VFD used under the JNNSM does not have formal MPPT. However, their DC link or bus-bar voltage (which is same as PV array voltage) operates near a point close to MPPT voltage.

TABLE I. Simulated PV Array Parameters

\begin{tabular}{ccccccc}
\hline $\begin{array}{c}\text { Type of } \\
\text { controller }\end{array}$ & $\begin{array}{c}\mathbf{V}_{\text {OC }} \\
(\mathbf{V})\end{array}$ & $\begin{array}{c}\mathbf{I}_{\mathrm{SC}} \\
(\mathbf{I})\end{array}$ & $\begin{array}{c}\mathbf{V}_{\mathrm{MAX}} \\
(\mathbf{V})\end{array}$ & $\begin{array}{c}\mathbf{I}_{\mathrm{MAX}} \\
(\mathbf{I})\end{array}$ & $\begin{array}{c}\mathbf{P}_{\mathrm{MAX}} \\
(\mathbf{W p})\end{array}$ & $\begin{array}{c}\text { Power } \\
\text { tracking } \\
\text { efficiency } \\
\%\end{array}$ \\
\hline SPCM & 270.45 & 13.18 & 214.67 & 11.84 & 2541.84 & 99.94 \\
VFD & 466.82 & 7.049 & 386.05 & 6.52 & 2518.40 & 86.66 \\
\hline
\end{tabular}
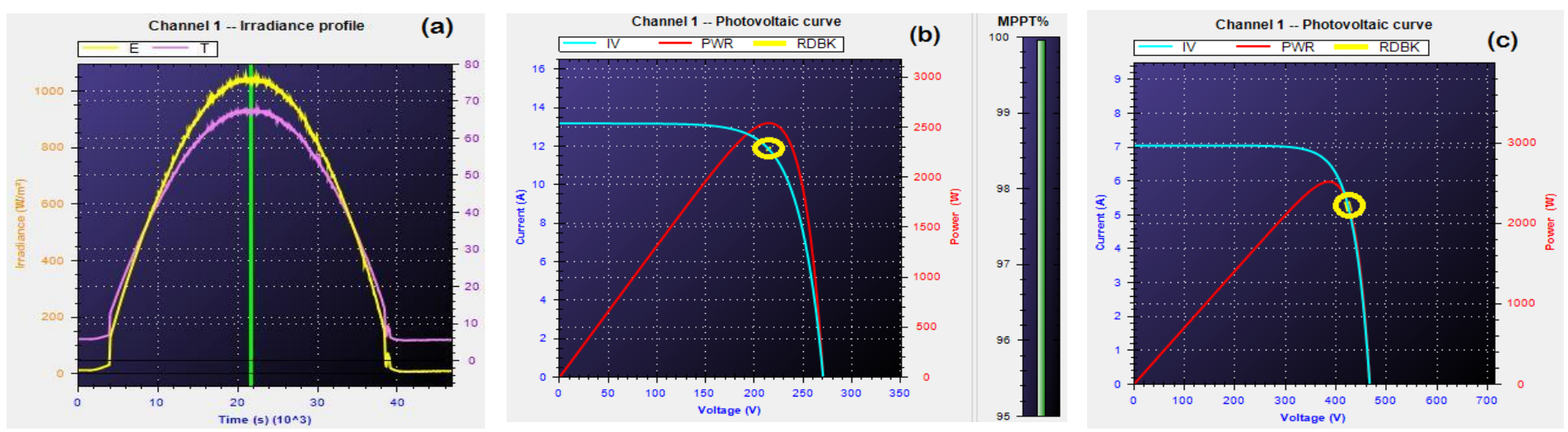

Fig. 2. (a) Whole day radiation profile, (B) I-V and P-V curves for SPCM and (C) I-V and P-V curves for VFD under similar condition

Figs. 2(a) - 2(c) show the simulated radiation profile for whole day, I-V and P-V curves of the array simulator for SPCM and VFD controllers under similar condition at an instant. It can be observed that for SPCM, operating point exactly positioned at maximum power point and therefore utilizes all the available power of PV array. In case of VFD based controller, the operating point is at load point which is away from maximum power point, and therefore a fraction of available power is lost. Data in table I provides the values of the $\mathrm{I}-\mathrm{V}$ parameters such as $\mathrm{V}_{\mathrm{OC}}, \mathrm{I}_{\mathrm{SC}}, \mathrm{V}_{\mathrm{MAX}}, \mathrm{I}_{\mathrm{MAX}}, \mathrm{P}_{\mathrm{MAX}}$ and efficiency of the tracking during the time of operation. The data given in table indicates that the tracking efficiency at the operating point for SPCM is $99.4 \%$ and is maintained consistently. For VFD controller the efficiency is about $86.6 \%$, and varies with input power and dynamic head. A detailed comparison of the power tracking efficiencies of controllers during a day of operation is displayed in Fig. 3, for three 
different heads $10 \mathrm{~m}, 18 \mathrm{~m}$ and $20 \mathrm{~m}$. SPCM operates between 99 to $99.5 \%$ for all the three heads during the day. The tracking efficiency of VFD based controller starts at $99 \%$, then quickly decreases as the day progresses, and maintains an average value of 93.2\%, 77.4\% and $72.2 \%$ depending on head of operation. The data reveal that at peak time of the day (noon) VFD's power tacking efficiency is the lowest, resulting in underutilization of the generated PV array power, which is the weakness of VFD. Further, it also decreases with an increase in operational head, reaches $72 \%$ at $20 \mathrm{~m}$ head. A clear understanding of the behavior of the controllers can be observed in Figs. 4(a) - 4(b). These figures provide details of the actual tracked power to that of available power for both the SPCM and VFD controllers. Fig. 4(a) belongs to SPCM; it clearly indicates a close match of the tracked and available power at any time of day for the three different heads. Fig. 4(b) shows similar details for VFD based controller, indicating a significant deviation between the available and actually tracked power, this difference further increases with head.

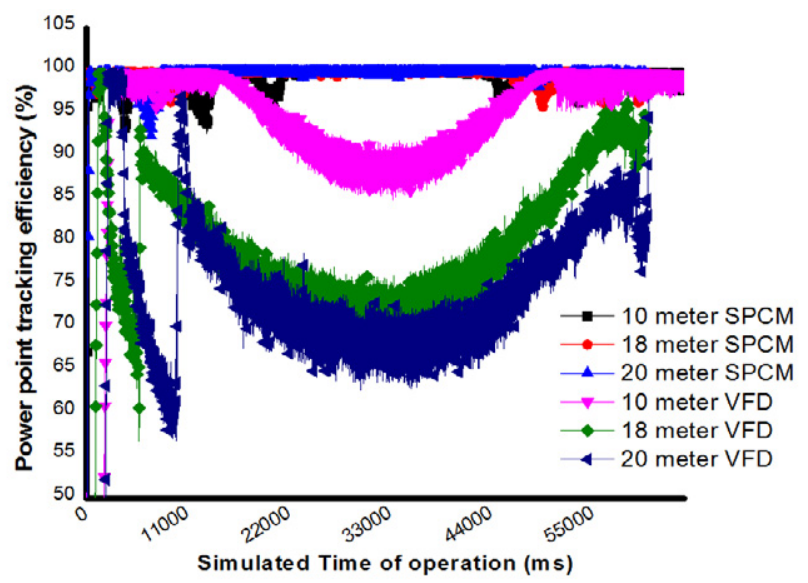

TABLE II. Average power tracking efficiency of controllers

\begin{tabular}{ccc} 
Head (meter) & \multicolumn{2}{c}{ Average power tracking efficiency $(\%)$} \\
\hline & SPCM & VFD \\
$\mathbf{1 0}$ & 99.3 & 93.2 \\
$\mathbf{1 8}$ & 99.6 & 77.4 \\
$\mathbf{2 0}$ & 99.6 & 72.2 \\
\hline
\end{tabular}

Fig. 3. Power tracking efficiencies of SPCM AND VFD controller at three different head
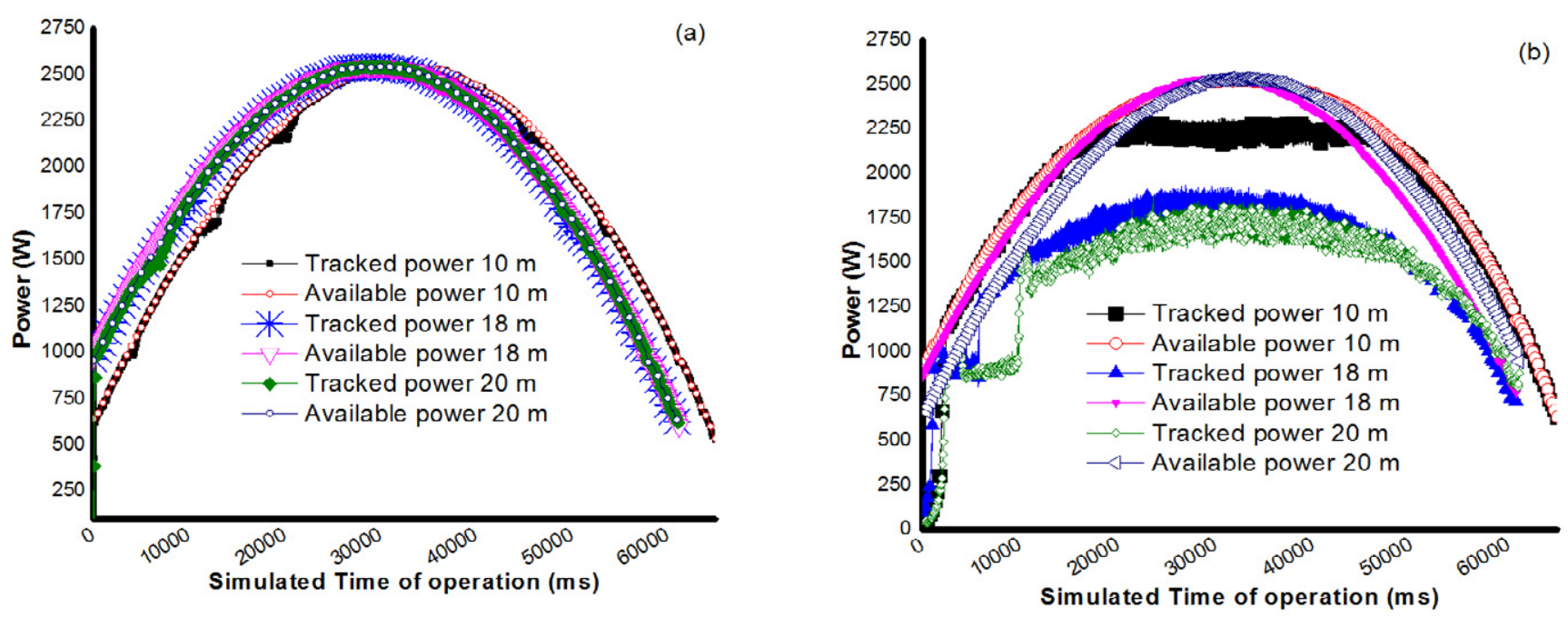

Fig. 4. Tracked and available input power at three different head for (a) SPCM (b) VFD

Further analysis of these controllers is carried using power factors (PF). The values of power factor (PF) and voltage/ frequency (V/F) ratio are plotted over a day for different load conditions. Details are given in Fig. 5(a) \& 5(b) indicating that the PF value for SPCM is about 0.9 throughout the day, except during early morning and late evening when the available power is low. For VFD, PF value is less than 0.8 and decreases with increasing load. For SPCM, V/F value is $\leq 4$, and is maintained constant 
throughout the operating time of the day. For VFD the value is high and varies from 4 to 5 . This revealed an important observation that the flux

density
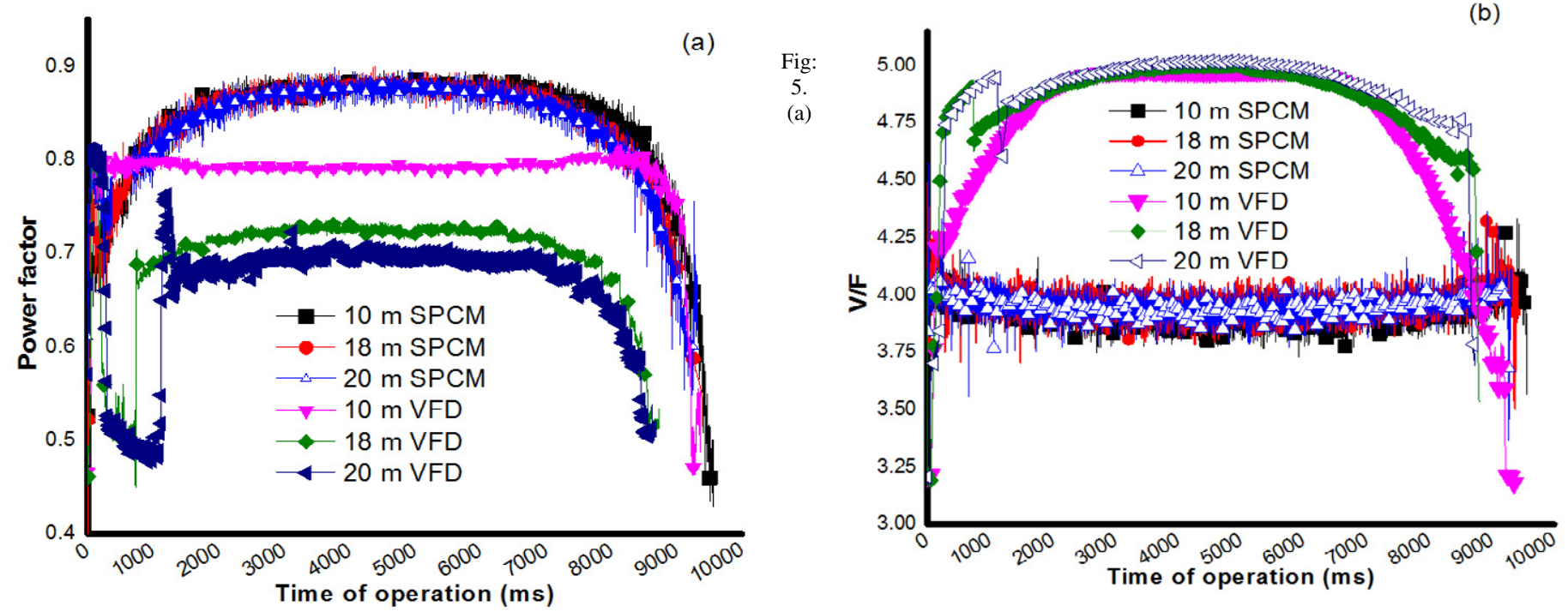

Power factor (PF) (b) V/F ratio throughout the day profile

in the motor is not able to maintain at the rated value in case of VFD based controller, resulting in poor power control. In SPCM, proper control of V/F ratio precisely controls the magnetic flux in the motor. In VFD controllers due to non-availability of MPPT arrangement, the input power operating point is forced to operate at a different point, as it tries to operate near constant voltage point set by DC-link/ bus-bar voltage. Table II shows the average power tracking efficiency, and head of operation, which indicates that MPPT efficiency of SPCM is constant for all heads, whereas for VFD controller this value decreases with increasing head, resulting in poor overall system efficiency.

\subsection{Power Quality}

In this section we discuss the quality of the AC power generated by the controllers and subsequently fed to motor. The indicators of the quality of AC power are defined in terms of four specific parameters; type of wave form \& frequency, Total Harmonic Distortion (THD), voltage spikes and crest factor. Figs. 6(a) \& 6(b) are the screen shots of the typical waveforms of voltage generated and supplied by the SPCM and VFD controllers. It can be seen that the waveform of SPCM is nearly a perfect sinusoidal wave (both voltage and current) with the crest factors (Vpeak/ $\mathrm{V}_{\mathrm{RMS}}$ ) 1.451 for voltage and 1.56 for current. On the other-hand, the VFD controller generates square waves with Pulse width modulation (PWM), with adjustable frequencies. It is known facts that VFD based controllers is mainly designed for the process industry, and are used specially for speed control of industrial motors to conserve the AC power and energy. Steven L. Mecker [Mecker, 1992] has analyzed the use of PWM waveform with motors. The wave form can create issues due to amplified thermal stress, and because of the nature of the high switching voltages of the drive, it may also increase stress on insulation.
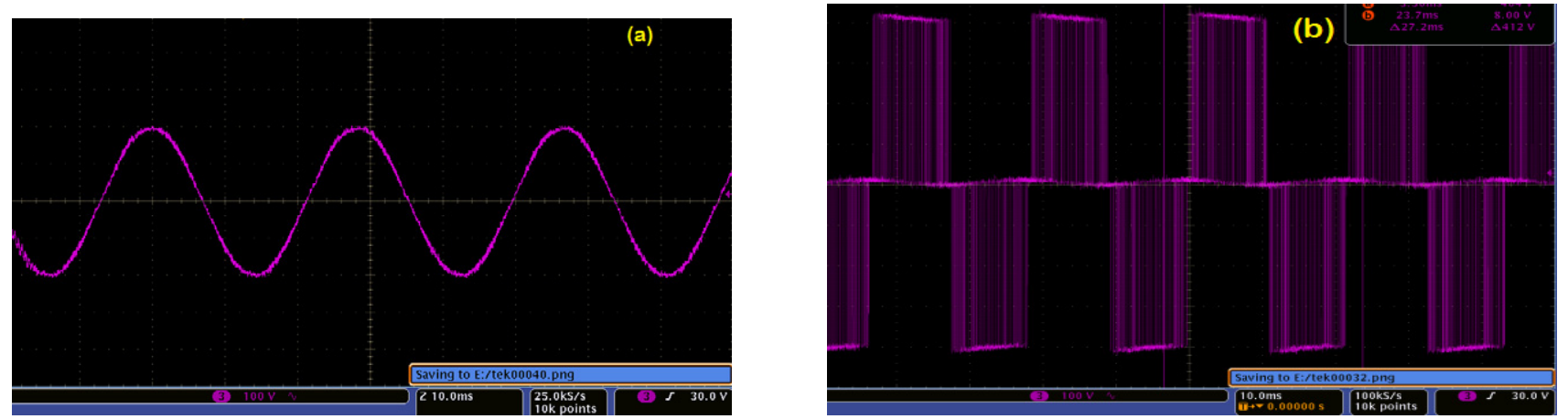

Fig. 6. Typical waveform of (a) SPCM (b) VFD 
Additionally, in SPV water pump application effect of length of extended cables connecting the motor and drive, causes additional noise generated by these VFD drives. The voltage spikes and ringing at the switching instances becomes pronounced with increasing motor cable length. Figs. 7(a) \& 7(b) show the Fourier analysis of the AC power fed by the controllers to motors at a distance of $60 \mathrm{~m}$. It is clear from Fig. 7(a) that the power generated by SPCM controller has only the fundamental component of frequency, and higher order harmonics are almost zero. The VFD power does contain significant magnitude of higher harmonics as shown in Fig. 7(b) (given in the inset) and hence the quality of power is poor. These harmonics result in additional losses and pulsating torque in the machine.
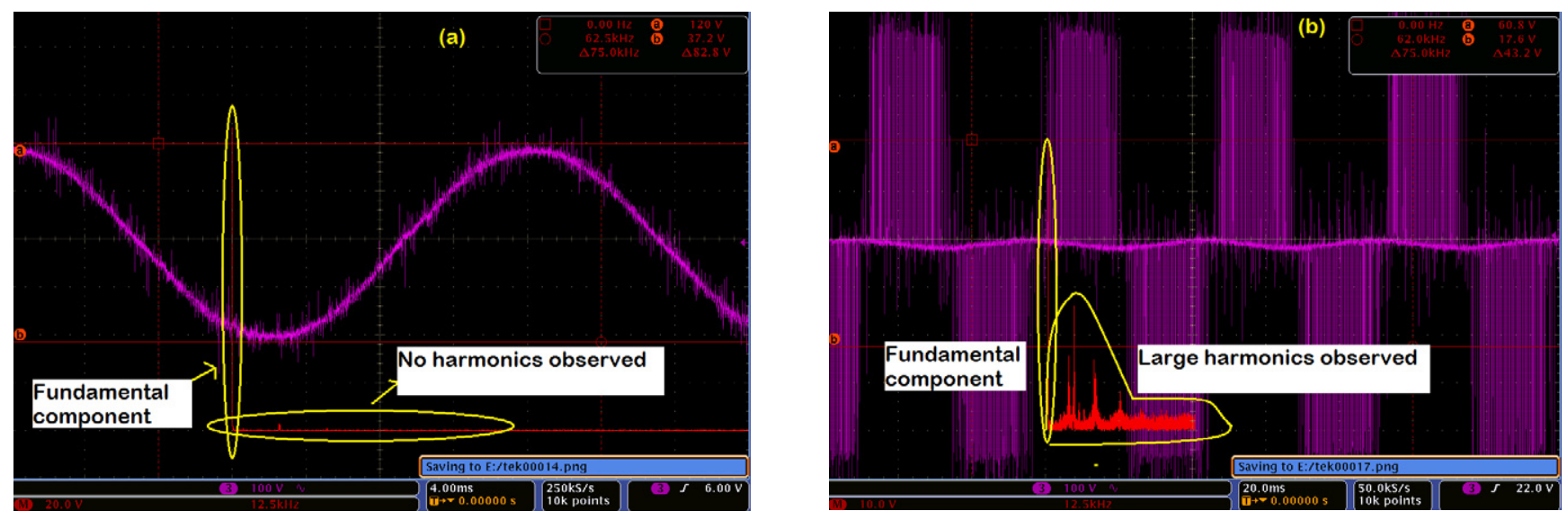

Fig. 7. Fast Fourier transform analysis of waveform for (a) SPCM \& (b) VFD using 60 meter cable length

Figs. 8(a) \& 8(b) are the magnified version of the waveform at motor terminals at a distance of $60 \mathrm{~m}$ for both the controllers. The SPCM waveform is still a perfect sine wave, without any significant voltage spikes and ringing. VFD waveform is square wave pulses with large voltage spikes and ringing at motor terminals. This may cause large stresses on the motor insulation. Steven L. Mecker [Mecker, 1992] also reported that thermal and insulation stresses mainly effect on three separate components: phase tophase, phase-to-ground, and turn-to-turn insulation in motor windings. By increasing the quality and thickness of the insulation material used in the stator, effect of these problems can be reduced. However in case of SPCM the problem of insulation does not occur because of high power quality and no additional arrangements are needed to reduce above mentioned stresses with the use of SPCM. So the use of SPCM will improve the quality and life of solar PV pumping system in real field.
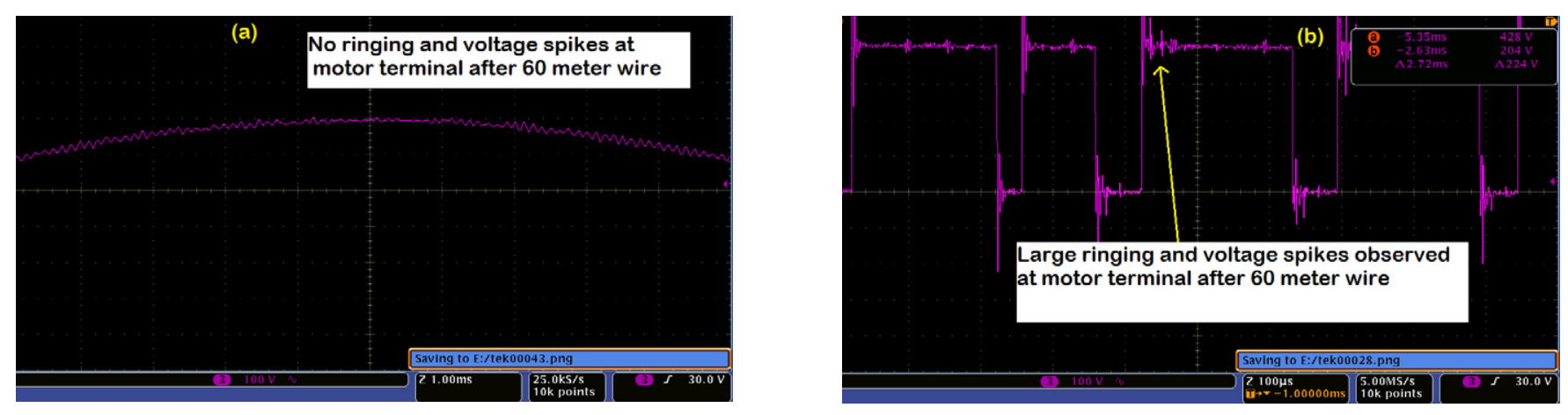

Fig. 8. Magnified version of waveform at motor terminal using 60 meter cable length for (a) SPCM (b) VFD

In terms of frequency also SPCM is better than the VFD. Frequency is an important parameter for SPV pumping system which decides the RPM of the motor and pump, higher frequency can provide higher speeds and more water output. The variable frequency power is offered by both the controllers, ranges from $20 \mathrm{~Hz}$ to $55 \mathrm{~Hz}$. Further, it is observed that maximum measured frequency of SPCM is about $52 \mathrm{~Hz}$ and maximum frequency of VFD based controller is $47 \mathrm{~Hz}$. This infers that SPCM controller generate high RPM and more water output. The details are discussed in the next section. 


\subsection{Comparison of Water output}

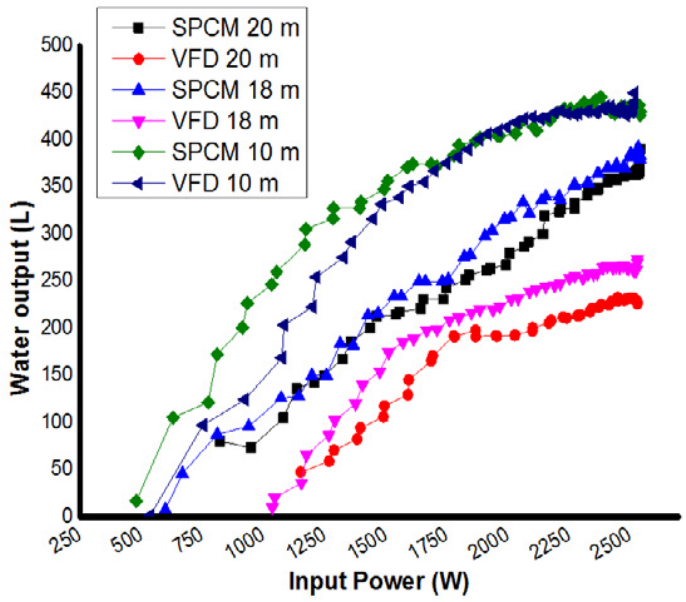

Fig. 9. Input power vs water output at three different head for SPCM and VFD

In this section the performances of both controllers are compared through quantity of water delivered at three different fixed heads when operated under similar conditions. In this experiment same pump is used and the capacity of simulated PV array and radiation profiles are maintained exactly same. Fig. 9 shows the variations of water output in Liters Per Minute (LPM) with input DC power. It shows that the LPM discharge of water decreases with the increase of the head from $10 \mathrm{~m}$ to $20 \mathrm{~m}$ measured at peak power for both the controllers. This reduction can be attributed to poor MPP tracking efficiency and poor magnetic flux management in the motor. For the same head of operation SPCM operated pump delivered higher water output than VFD based. This is due to efficient MMP tracking so that more energy is extracted from PV array and supplied to motor and pump. Within the simulated time of operation (55 minutes), at 20 meter head the SPCM operated pump delivered 14,000 liters of water; however the VFD driven pump could deliver only 8000 liters, which is about $70 \%$ higher than VFD. This is the most important observation, considering the water output as main objective for any SPV pump. The graph in Fig. 9 shows the comparison of water outputs at peak input power at three different heads by the same motor and pump.

TABLE II. Parameters related to water discharge for SPCM and VFD based system at three different head

\begin{tabular}{|c|c|c|c|c|c|c|c|c|c|c|}
\hline \multirow[t]{2}{*}{ Head } & \multicolumn{5}{|c|}{ SPCM } & \multicolumn{5}{|c|}{ VFD } \\
\hline & $\begin{array}{l}\text { Starting of } \\
\text { discharge } \\
(W p)\end{array}$ & $\begin{array}{c}\text { Ending of } \\
\text { discharge } \\
(W p)\end{array}$ & $\begin{array}{c}\text { Water } \\
\text { discharge } \\
\text { at rated } \\
\text { peak power } \\
\text { of the } \\
\text { array } \\
(\text { LPM })\end{array}$ & $\begin{array}{c}\text { Wire to } \\
\text { Water } \\
\text { Efficiency } \\
(\%)\end{array}$ & $\begin{array}{c}\text { Overall } \\
\text { system } \\
\text { efficiency } \\
(\%)\end{array}$ & $\begin{array}{c}\text { Start of } \\
\text { discharge } \\
(W p)\end{array}$ & $\begin{array}{c}\text { End of } \\
\text { discharge } \\
\text { (Wp })\end{array}$ & $\begin{array}{c}\text { Water } \\
\text { discharge } \\
\text { at rated } \\
\text { peak power } \\
\text { of the } \\
\text { array } \\
(\text { LPM })\end{array}$ & $\begin{array}{c}\text { Wire to } \\
\text { Water } \\
\text { Efficiency } \\
(\%)\end{array}$ & $\begin{array}{c}\text { Overall } \\
\text { system } \\
\text { efficiency } \\
(\%)\end{array}$ \\
\hline 10 & 793 & 330 & 455 & 36.91 & 36.6 & 1158 & 460 & 432 & 32.77 & 30.7 \\
\hline 18 & 968 & 638 & 390 & 43.96 & 43.5 & 1178 & 764 & 273 & 39.24 & 30.4 \\
\hline 20 & 989 & 777 & 370 & 46.21 & 46.0 & 1679 & 1027 & 235 & 38.07 & 27.5 \\
\hline
\end{tabular}

Table III displays the additional data on the water output for the same motor and pump system when operated with the controllers. Over all system efficiency is defined as ratio between potential energy in terms of water output to the energy available at the PV array output assuming $100 \%$ power tracking. Wire to water efficiency is defined as the ratio between potential energy in terms of water output to the actual energy supplied by the PV array. The threshold power for water discharge in case of SPCM is lower than the VFD based system. Apart from other observations on start and end input powers, most significant observation is that at 20 meter head, the difference between delivered water outputs of controllers under rated peak input power conditions is around 57 $\%$, with SPCM controller is leading. The overall system efficiency of SPCM operated pump is $18.5 \%$, higher than VFD operated pump at $20 \mathrm{~m}$ head. This comparison clearly establishes the supremacy of the performance of the SPCM controller over the conventionally used VFD controllers. 


\section{CONCLUSION:}

A detailed comparison of SPCM and VFD based controllers used for driving Solar Photovoltaic (SPV) water pumping systems is presented. SPCM having variable frequency inverter $(>94 \%)$ and MPPT $(>99 \%)$ offered the best performance throughout the operational range, compared to the Variable Frequency Drives (VFD). This paper presented an exhaustive study of SPCM and VFD based controllers in terms of their operational performance at three different heads. The quality of output power and quantity of the total water delivered using the same motor and pump under similar conditions has been studied for $3 \mathrm{hp}$ pump. SPCM with highest MPPT efficiency of $99.4 \%$, lowest THD of $<3 \%$ pumped 30 to $70 \%$ more water under same head than the same pump with VFD controller. The overall system efficiency of pumping system coupled with SPCM is $18.5 \%$ more than that of VFD based controller at $20 \mathrm{~m}$ head. As well as higher power quality delivered by SPCM enriched life expectancy of the motor.

\section{ACKNOWLEDGMENT}

This research is based upon work supported in part by the Solar Energy Research Institute for India and the U.S. (SERIIUS) funded jointly by the U.S. Department of Energy subcontract DE AC36-08G028308 (Office of Science, Office of Basic Energy Sciences, and Energy Efficiency and Renewable Energy, Solar Energy Technology Program, with support from the Office of International Affairs) and the Government of India subcontract IUSSTF/JCERDC-SERIIUS/2012 dated 22nd Nov. 2012

\section{REFERENCE:}

Avetta, P., Bella, F., Bianco Prevot, A., Laurenti, E., Montoneri, E., Arques, A., Carlos, L.,2013.Waste Cleaning Waste: Photodegradation of Monochlorophenols in the Presence of Waste-Derived Photosensitizer. ACS Sustainable Chem. Eng. 1, 1545-1550. doi.org/10.1021/sc400294z.

Benghanem, M., Daffallah, K.O., Alamri, S.N., Joraid, A.A., 2014. Effect of pumping head on solar water pumping system. Energy Conversion and Management. 77, 334-339.

Bonnett, A. H., 1996. Analysis of the Impact of Pulse-Width Modulated Inverter Waveforms on A.C. Induction Motors. IEEE-IAS Transactions. 32,68 - 75.

Chiappone, A., Bella, F., Nair, J. R., Meligrana, G., Bongiovanni, R., Gerbaldi, C., 2014. Structure-Performance Correlation of Nanocellulose-BasedPolymer Electrolytes for Efficient Quasi-solid DSSCs. ChemElectroChem. 1, 1350 - 1358. DOI: 10.1002/c elc.201402051.

Cuadrosa, F., López-Rodríguezb, F., Marcosb A., Coelloc J., 2004. A procedure to size solar-powered irrigation. Solar Energy .76, $465-473$.

Daugherty, R. H., Wennerstrom, C. H., 1990. Need for industry standards for AC induction motors intended for use with adjustable frequency controllers. IEEE PCIC. 1175-1185.

Dursuna, M., Özdenb, S., 2014. Computers and Electronics in Agriculture. Computers and Electronics in Agriculture. 102, $120-126$.

Ebaida, M.S.Y., Qandilb, H., Hammadb. M., 2013. A unified approach for designing a photovoltaic solar system for the underground water pumping well-34 at Disi aquifer. Energy Conversion and Management. 75, 780-795.

Glasnovica, Z., Margetab J., 2007. A model for optimal sizing of photovoltaic irrigation water pumping systems. Solar Energy. 81, 904-916.

Hamidata, A., Benyoucef, B., 2009. Systematic procedures for sizing photovoltaic pumping system, using water tank storage. Energy Policy $37,1489-1501$. http://mospi.nic.in/ accessed on 12 Feb 2015.

http://www.mnre.gov.in/ accessed on 12 Feb 2015

Hyypio, D. B., 1997. A Model for Predicting Voltage Endurance of Magnet Wire Film Subjected to Inverter PWM Voltage Waveforms with Transient Overshoot. IEEE-APEC. 24-30.

Kassem, M. A., 2012. MPPT control design and performance improvements of a PV generator powered DC motor-pump system based on artificial neural networks. Electrical Power and Energy Systems 43, 90-98.

Mecker, S. L., 1992. Considerations In Derating Induction Motors For Applications On Variable Frequency Drives. Pulp and Paper Industry Technical Conference. 191-197.

Melhorn, C. J., Tang, Le., 1995. Transient Effects of PWM Drives on Induction Motors. IEEE I\&CPS Conference, San Antonio. 33 , 1065 - 1072.

Mohammedi, A., Mezzai, N., Rekioua, D., Rekioua, T., 2014. Impact of shadow on the performances of a domestic photovoltaic pumping system incorporating an MPPT control: A case study in Bejaia, North Algeria. Energy Conversion and Management. 84, 20-29.

Moulay-Idriss, C., Mohamed, B., 2013. Application of the DTC control in the photovoltaic pumping system. Energy Conversion and Management. 65, 655-662.

Mozaffari Niapour, S.A.KH., Danyali, S., Sharifian, M.B.B., Feyzi, M.R., 2011. Brushless DC motor drives supplied by PV power system based on Z-source inverter and FL-IC MPPT controller. Energy Conversion and Management. 52, 3043-3059.

Persson, E., 1992. Transient Effects in Application of PWM Inverters to Induction Motors. IEEE-IAS Transactions. 28, 1095-1101.

Rehmana, S., Al-Hadhramia L. M., Mahbub Alamb, Md.,2015. Pumped hydro energy storage system: A technological review. Renewable and Sustainable Energy Reviews. 44, 586-598.

Sastry, O.S., Agarwal S., Adiraju, D., Kumar, R., Bandopadhyay, B., 2013. Performance evaluation of solar photovoltaic lighting and water pumping systems in India. 26th European Photovoltaic Solar Energy Conference and Exhibition 25, 351-370.

Senol, R., 2012. An analysis of solar energy and irrigation systems in Turkey. Energy Policy 47, 478-486.

Shin, S. M., Jung, J.Y., Park, M.J., Song, J.W., Lee. J.H., 2015. Catalyst-free hydrogen evolution of Si photocathode by thermovoltage-driven solar water splitting. Journal of Power Sources.279, 151-156.

Kamlesh Yadav: Mr. Kamlesh Yadav is a researcher at National Institute of Solar Energy (NISE), India. He has more than 3 year experience in performance testing of controller, Inverter and water pumping system. His research interest includes performance and reliability of PV systems and its applications in real outdoor condition.

Oruganti Sankara Sastry: Dr. Sastry is a senior scientist in Solar Photovoltaic division at NISE with more than 30 year of experience in Solar photovoltaic. He received his Phd from Indian Institute of technology Delhi. His research area includes performance and reliability of photovoltaics and its applications. 
Rupesh Wandhare: Dr. Wandhare has done his Phd from Indian Institute of technology Bombay and currently working with Kisan Solar, India as Chief research officer. His research area includes designing and performance evaluation of controller, inverter and its applications.

Nimesh Sheth: Mr Sheth is a founder of Kisan solar, MS in Electrical Engg., from University of Southern California. His area of interest is semiconductor, PV cell technology, PV system engineering and applications.

Mithilesh Kumar: Mr. M. Kumar is a researcher at NISE, India. He has more than 3 year experience in performance testing of controller and inverter.

Birinchi Bora: Mr. B. Bora is a researcher at NISE, India. His area of interest is performance modeling of PV systems.

Rashmi Singh: Ms. R. Singh is a researcher at NISE, India. Her area of interest is solar cell characterization and its performance modeling.

Renu: Ms. Renu is a researcher at NISE, India. Her area of interest is performance evaluation of Solar PV water pumping system and its applications.

Arun Kumar: Mr. A. Kumar is a scientist at NISE, India. His area of interest is performance evaluation of Solar PV system and its applications. 